\title{
The disjoint verb form and an empty Immediate After Verb position in Makhuwa*
}

\author{
Jenneke van der Wal \\ Leiden University (LUCL)
}

The Bantu language Makhuwa makes a distinction between conjoint and disjoint verb forms. Two hypotheses are made from generalisations on the distribution of the conjoint and disjoint verb forms in Makhuwa. 1) The verb appears in its conjoint form when a focal element occupies the Immediate After Verb (IAV) position; 2) the verb appears in its disjoint form when the IAV position is empty. A syntactic analysis is provided that accounts for these hypotheses if the IAV position is defined in terms of structural rather than linear adjacency between two heads in a direct c-command relation.

In the syntactic analysis two focus projections are proposed: one under TP (Ndayiragije 1999) hosting the disjoint morpheme and one under vP, to whose specifier focal elements move. Non-focal elements remain in-situ. This analysis accounts both for the strong adjacency requirement of a conjoint verb form and its focal object and for the empty IAV position that requires a verb to appear in its disjoint form.

\section{Introduction}

\subsection{Makhuwa and the conjoint/disjoint distinction}

The theory explored in this paper is primarily applied to the Bantu language Makhuwa (also spelled Emakhuwa or Macua, P.30), specifically the variant Enahara spoken on Ilha de Moçambique and in the surrounding coastal area in the north of Mozambique. This language and variant uses the so-called conjoint (CJ) and disjoint (DJ) verb forms. The terms "conjoint" and "disjoint" were first

\footnotetext{
* I want to thank my informants Ali Pwanale, Joaquim Nasario and Momade Ossumane, the members of the Bantu Syntax Team in Leiden (Lisa Cheng, Thilo Schadeberg, Leston Buell and Kristina Riedel) as well as Laura Downing and the audience at the workshop Information Structure in Bantu Languages in Berlin.
} 
used by Meeussen (1959) in his description of Kirundi. He noticed two different verb forms in one tense and described these as a difference in the relation of the verb with the element following it. Hence the term conjoint (< French, 'united') for a combination V X that is very close and the term disjoint ('separated') for a structure in which the verb has a looser relation with the following element. These originally French terms are now also used in English, together with conjunctive and disjunctive. Other terms such as 'weak/strong' and 'short/long' have also been used, but these turned out to inadequately describe the meaning of the two verb forms. In this paper I use the terms conjoint and disjoint.

In Makhuwa there are two noticable markings of the $\mathrm{CJ} / \mathrm{DJ}$ verb forms. First there is a segmental difference in the verb. In the present tense in (1) a separate disjoint morpheme -aa- is visible. In the perfect tense in (2) there still is a difference, but it is hard (if not impossible) to segmentalize a DJ morpheme. ${ }^{1}$

present $^{2}$

(1) a. DJ o-náá-thípa

3sg-PRES.DJ-dig

b. CJ o-n-thípá nlittí

3sg-PRES-dig 5.hole 'she's digging'

'she digs a hole'

perfect
a. DJ k-oo-rúpa
1sg-PERF.DJ-sleep
b. CJ
ki-rup-alé nkwaártu
1sg-sleep-PERF 18.room

'I slept'

'I slept in the room'

\footnotetext{
${ }^{1}$ Only the disjoint verb form is glossed for the choice of verb form ('DJ'); the conjoint form is taken as the default. In this paper I only consider affirmative declarative sentences, since a $\mathrm{CJ} / \mathrm{DJ}$ distinction is absent in negative and relative sentences in Makhuwa; but note that this is not the case in all Bantu languages. Other past tenses apart from the perfect tense also segmentally and tonally mark the CJ/DJ distinction.

2 Abbreviations and symbols used in this paper: $1 / 2 / 3$ etc (noun classes), $1 \mathrm{sg} / \mathrm{pl}$ ( $1^{\text {st }}$ person singular/plural), A (answer), CAUS (causative), CJ (conjoint), CONN (connective), COP (copula), DEM (demonstrative), DJ (disjoint), DS (dummy subject), DUR (durative), FV (final vowel), H (high tone), IMPF (imperfective tense), irr (irrealis), L (low tone), LOC (locative), NARR (narrative), NEG (negative), OM (object marker), OPT (optative), PASS (passive), PAST (past tense), PERF (perfective tense), PERS (persistive), POSS (possessive), PRES (present tense), SM (subject marker), P2 (past), PL (predicative lowering), Q (question), REDUPL (reduplication), REL (relative), REM (remote tense), REP (repetative), RESP (respect), Ittl (retroflex voiceless stop). Liaison is indicated by an apostrophe, high tones are indicated by an accute accent (on or before the element), low tones are unmarked.
} 
Second there is a tonal difference. The tonal part of the CJ/DJ marking in Makhuwa is not on the verb, but in a different tonal pattern occurring on the element following a CJ form (Stucky 1979, Katupha 1983). The object of a DJ verb form has the same tonal pattern as in citation form as shown in (3a), whereas the object of a CJ verb form undergoes so-called "lowering" (Schadeberg and Mucanheia 2000): the first underlying high tone is removed and a final high tone is added ( $3 b)$.
a. meéle
kinááthítá
meéle
1sg-PRES.DJ-pound 6.maize
'maize'
b. DJ
kinthítá meelé
1sg-PRES-pound 6.maize
c. CJ
'I pound maize'
1sg-PRES-pound 6.maize
'I pound maize'

One major difference between the verb forms is their phrase-final distribution. The conjoint form can never appear phrase-finally (4b); i.e., some object or adjunct has to follow $(4 \mathrm{c}, \mathrm{d})$. The disjoint form, on the other hand, may occur sentence-finally (4a), but does not need to (i.e. something can still follow the DJ verb form, as shown in (4e)). The object following a disjoint form is most likely interpreted as known or old information.
a. DJ enyómpé tsi-náá-khúura
10-cows 10-PRES.DJ-eat
'the cows are eating'
b. CJ *enyómpé tsi-n-khúura
10-cows 10-PRES-eat
c. CJ enyómpé tsinkhúúrá malashí
cows eat grass 'the cows eat grass'
d. CJ enyómpé tsinkhúúrá orattáni
cows eat at lake 'the cows eat at the lake'
e. DJ enyómpé tsináákhúúrá maláshi
cows eat.DJ grass
'the cows eat grass'

The distribution of the conjoint and disjoint verb form will be shown to be dependent on the information structure of the sentence, specifically on the position of focus. In the next section some background is given on this issue, which will later be linked to the CJ/DJ distinction. 


\subsection{Focus and the Immediate After Verb position}

Van Valin (1999) explains certain typological differences in focus structures by examining the interaction of rigidity vs. flexibility of syntax and focus structure. A language like English has a rigid syntax and a flexible focus structure in the sense that the language does not readily permit changing the word order of a sentence, but rather moves the stress to the focused word (5).

Kim sent the book to Leslie yesterday

Kim sent the book to Leslie yesterday

Kim sent the book to Leslie yesterday

A language with a flexible syntax and a rigid focus structure would rather have a fixed position for prominence and change the word order to match the focused element and this position. The syntax adapts to the focus structure, not the other way around. Italian and Spanish are examples of this type of languages, but also Bantu languages like Setswana and Sesotho (and, as will be seen, also Makhuwa) organize their focus structure by changing the word order instead of the focus structure. In these SVO languages there is an absolute constraint against focal elements appearing preverbally (Van Valin 1999, Zerbian 2006). Subjects must be "highly topical, old, given information" (Demuth 1989). The potential focus domain "does not encompass the entire clause in a simple sentence, as in English [...]; rather it is restricted to the verb and following elements" (Van Valin 1999).

Watters (1979) establishes the "immediate after verb" (IAV) position as the focus syntactic position Aghem, a Grassfields Bantu language. He convincingly shows that a focused element, for example in an answer to a whquestion, moves to this immediate after verb position. In (6a) the adverbial clause 'in the farm' is in its typical sentence-final position. In answer to a question about the place the friends ate the fufu, 'in the farm' provides new information and is in focus: án 'sóm (in the farm) is moved to the IAV position (6c). 
Aghem (Watters 1979: 147)

(6)
a.
fü
friends SM P2 eat fufu in farm
'the friends ate fufu in the farm'
b. fúl á mò ź ghê bé-'k5
friends SM P2 eat where fufu
'where did the friends eat fufu?'
c. (fîl á mò zî) án 'sóm (bé-'kó)
friends SM P2 eat in farm fufu
'(the friends ate fufu) in the farm'

So far I have shown that there is a distinction between conjoint and disjoint verb forms in the language Makhuwa, how this distinction is marked and what its basic distribution is. I have also given data from Aghem with the observation that the Immediate After Verb position is a focus position. In section 2 I first come back to Van Valin's (1999) statement that focal elements should not appear preverbally. I then claim that the position immediately after a conjoint verb form is the position for focus in Makhuwa, much like in Aghem. Section 3 provides arguments for the hypothesis that focal elements cannot immediately follow a disjoint verb form or, phrased more strongly, that the verb appears in its disjoint form when the IAV position is empty. In section 4 the syntax of the IAV position is analysed and it is shown that the observations and hypotheses made in earlier sections follow from this analysis.

\section{Focus in the $\mathrm{IAV}_{\mathrm{CJ}}$ in Makhuwa}

\subsection{Constraint against preverbal focus}

The first observation made is that focal elements can not appear preverbally. For a simple declarative sentence this is indeed the case. Makhuwa, being an SVO language, typically has sentences with a topic-comment structure. In stories, a new participant is introduced in the text in the position after the verb and the next sentence makes reference to this participant in the position before the verb, the typical subject position. In (7a) 'the ghost of the grandmother' is introduced. Now that grandma's ghost is known information, it serves as a topic and occurs as the (pro-dropped) subject ( $7 b$ ). We then get some new information about the 
now known participant; in this example we learn that the ghost orders the protagonist to start eating dark shima. ${ }^{3}$

(7) a.

b.

\section{waa-núú-khúmá nnépá wa á-píp' ínyu.}

3.REM-PERS.DJ-go.out 3.ghost 3.CONN RESP-grandma 2.RESP.POSS

'the ghost of your grandmother appeared'

waa-hímyá wiírá eshímá yoóríipa m-patshér-éke ótsha

3.REM-say that 9.shima 9.dark 2.RESP-begin-OPT 15.eat

'it said that you should start eating dark shima'

When the object is already known or old information, it often moves to the preverbal position. We get either a topic expression (8) or a passive construction (9), where the theme is the syntactic subject. That the theme is known in these examples cannot not only be concluded from the context, but also from the use of the demonstrative.

a. DJ miẃwá íye ko-haála

4.thorns 4.DEM 1sg.PERF.DJ-plant

'those thorn bushes, I planted them'

b. DJ nlópwáná oyó ki-ná-m-phéela

1.man 1.DEM 1sg-PRES.DJ-1.OM-want

'that man, I want him'

a. mí ki-thip-alé nlittí

1sg 1sg-dig-PERF 5.hole

'I dug a hole'

b. $\quad$ nlíttí noó-thíp-íy-á

5.hole 5.PERF.DJ-dig-PASS-FV

'the hole was dug'

New information occurring in a passive construction usually follows the verb. Example (10) comes from a story about different kinds of food. It is mentioned that now is the time for cassava and that today the man will have shima for dinner. The shima is newly introduced and follows the (passive) verb (in contrast to $(9 b)$ ). In the next sentence the man claims that he does not eat dark shima

${ }^{3}$ Shima is the staple food of East Africa. It is a stiff porridge made of maize flour (white shima) or cassava flour (dark shima), in Swahili known as 'ugali'. 
made from cassava. We know the man and we know the shima and in this sentence all the arguments precede the verb.

(10) a.

vánó yoo-rúw-íy-a eshíma

now 9.PERF.DJ-cook-PASS-FV 9.shima

'this time shima was cooked'

b. hw-íra-ka: "mí, eshímá yoóríipa n-ki-ń-tsha."

NARR-say-DUR: 1sg, 9.shima 9.dark NEG-1sg-PRES-eat

'and he said: "I don't eat dark shima" ،

I have established that what precedes the verb is not focal and that in Aghem what immediately follows the verb is focal. In the next section it will be shown that this also holds for Makhuwa and that it interacts with the CJ/DJ distinction.

\subsection{Focus immediately follows the conjoint verb}

The IAV position is also a focus position in Makhuwa, but only when the verb is conjoint. This can be seen in the tonal lowering, the position of question words and the position of focused elements in question-answer pairs.

Tonal lowering is another mechanism to mark focus. It is different from, but cooperating with, the CJ/DJ distinction, see for example also Schadeberg and Mucanheia (2000). It identifies a unique position, and only the first element following a CJ verb form in a double object construction is tonally lowered. In both sentences in (11) the first element following the verb has the tonal pattern LLH, whereas the second still has its LHL form, which it also has in its citation form.
(11)
a. CJ ni-m-váhá maatsí enúni 1pl-PRES-give 6.water 10.birds
b. CJ ni-m-váhá enuní maátsi
(LLH) (LHL)
1pl-PRES-give 10.birds 6.water
'we give the birds water'

Question words are often analysed as being inherently focused. In Makhuwa wh-words have a strong preference to immediately follow the CJ verb form (12b). Most questions in recorded stories have a CJ form with the wh-word immediately following it, and this is also the structure the informants first give when asked to translate a question. Although grammatical, a question where the wh-word is separated from the verb is the less preferred one (12c). Still, a 
question with a conjoint verb from is always better than a question using the disjoint form of the verb $(12 \mathrm{~d}, \mathrm{e})$. The question examples in (12) are all intended to mean 'what did you leave on the table?'.
a. CJ ki-hiy-alé eliivurú wameétsa
1sg-leave-PERF 9.book 16.table
'I left the book on the table'
b. CJ o-hiy-alé esheení wameétsa?
2sg-leave-PERF what 16table
'what did you leave on the table?'
c. CJ o-hiy-alé wameétsá eshéeni?
2sg-leave-PERF 16.table what
d. DJ *woo-híyá eshéeni waméetsa?
2sg.PERF.DJ-leave what 16.table
e. DJ ??woo-híyá wameétsá eshéeni?
2sg.PERF.DJ-leave 16.table what

A third argument for the claim that the position immediately after a conjoint form is a focus position is found in question-answer pairs. The new information in the answer (namely the element that was questioned) is focused and immediately follows the CJ verb, whether this is its basic position or not. In (13a) the direct object is focused, whereas in (13b) the indirect object is in focus and both are in the IAV position.
2sg-1.OM-give-PERF what 1.Teresinha
'what have you given Teresinha?'
a. Q o-m-vah-alé esheení Teresínya?
A ki-m-vah-alé ekanetá (Teresínya)
1sg-1OM-give-PERF 9.pen (1.Teresinha)
'I gave (her/Teresinha) a pen'


b. Q o-m-vah-alé páni ekanéta?

2sg-1OM-give-PERF who 9.pen

'who did you give a pen?'
A ki-m-vah-alé Teresínyá (ekanéta)
1sg-1OM-give-PERF 1.Teresinha (9.pen)
'I gave (it/a pen) to Teresinha'

The position immediately after the conjoint verb form is thus established as a focus position, which implies that focused elements should (always) follow a conjoint verb form. ${ }^{4}$ The hypothesis holds true, for example, when the object is contrastively focused as in (14).

$\begin{array}{lll}\text { n-ki-var-álé } & \text { ehópá, } & \\ \text { NEG-1sg-catch-PERF 9.fish } & \text { 'I didn't catch fish, } \\ \text { CJ } & \begin{array}{l}\text { ki-var-alé } \\ \text { e-phwetsá }\end{array} & \\ & \text { 1sg-catch-PERF 9.octopus } & \text { I caught octopus. }\end{array}$

After a CJ verb form the object can not only have contrastive focus, but also new information focus. Example (15) is the most natural answer to the question 'what did the woman carry?'. The same sentence can also be perfectly used to answer the questions 'what did the woman do?' or 'what happened?', where either the VP or the whole sentence is in focus. It is widely accepted that focus can project, meaning that an entire constituent can be interpreted as focused even if only a subconstituent of it is actually marked for focus (by prosody, for example; see Selkirk 1984). The postverbal element in Makhuwa would fall under the projected wide scope reading of the focus when used in answer to the wider questions and is thus still (part of) the focus.

$$
\begin{aligned}
& \text { CJ nthíyána o-kush-alé eliivurú } \\
& \text { 1.woman 1-carry-PERF 9.book } \\
& \text { 'the/a woman carried a/the book' }
\end{aligned}
$$

4 Focused elements follow a conjoint form in simple declarative sentences. It is also possible to make a cleft sentence in order to focus something. 
In this section I have shown that non-focal elements precede the verb and that focal elements follow a conjoint verb form. Put more specifically, it was shown that they immediately follow a conjoint verb form, thus occupying the IAV position.

\section{The IAV position and the disjoint verb form}

If focal elements immediately follow a conjoint verb form, what immediately follows a disjoint verb form is not expected to be focal. Combined with the observations about the IAV position, the implication that explains the occurrence of the disjoint form is the following: if the Immediate After Verb position is empty, the verb appears in its disjoint form. Non-focused material is assumed to be in a position other than the structurally defined IAV, leaving this position empty.

\subsection{Disjoint verb form phrase-finally}

The most straightforward argument in favour of this hypothesis is the distribution of the two verb forms in sentence-final position. The conjoint form needs a following element and is ungrammatical without it, whereas the disjoint form can (but does not need to) be in sentence-final position. If nothing follows the verb, obviously the position after the verb is empty and the verb has its DJ form. This situation is found in sentences with an intransitive use of the verb as in (4) (repeated below) and in passive sentences (16a). What usually follows the verb in an active sentence now precedes the verb, leaving the verb in sentencefinal position. Note, however, that the passive sentence in (16b) has a (focal) element following the verb and the verb now occurs in its conjoint form.

(4) a. DJ enyómpé tsi-náá-khúura

10.cows 10-PRES.DJ-eat 'the cows are eating'
b. CJ *enyómpé tsi-n-khúura
10.cows 10-PRES-eat

c. CJ enyómpé tsi-n-khúúrá malashí

10.cows 10-pres-eat 6.grass 'the cows eat grass'

(16) a. DJ moóró woo-páríhel-íy-a

3.fire 3.PERF.DJ-light-PASS-FV

'the fire has been lighted' 


\section{b. CJ moóró o-parihel-iy-é nkíńtááli}

3.fire 3-light-PASS-PERF 17.compound

'fire has been lighted in the compound'

\subsection{Disjoint verb form and old information}

Creissels (1996) claims that an element following a DJ verb form is in fact "a topicalized phrase linked to the clause without being strictly speaking a part of it" (p.112). This can be demonstrated for a number of cases in Makhuwa, but not all. Topicalizing the old information correlates with object marking, as can be observed in Tswana, for example. In Makhuwa this pronominal marking is absent. ${ }^{5}$ In order to know whether or not a postverbal element is old or non-focal information, one is dependent on the context and the use of demonstratives. That the old information follows a DJ verb form can be seen in (17). The first example comes from a story where a man has just slaughtered a goat and now buried it. In (17b) a hunter has entered a bakery and demanded bread, which is given to him, after which he takes it. The post-DJ element (the goat/bread) is modified by a demonstrative. It is old information and not focal.

(17) a. DJ oo-thípélá epúrí ile

1.PERF.DJ-bury 9.goat 9.DEM 'he buried that goat'

b. DJ oo-kúshá ephááú iyé

1.PERF.DJ-carry 10.bread 10.DEM 'he took that bread'

\subsection{Disjoint verb form and intervening elements}

The disjoint form is also used when something intervenes between the verb and the object (18a). With the intended "neutral" reading that has new information focus on the object (that follows the verb, but not immediately), the conjoint form is ungrammatical (18bi). Only with a strong contrastive focus on the adverb is it grammatical to use the CJ form (18bii). ${ }^{6}$

\footnotetext{
${ }^{5}$ Only noun classes $1 / 2$ are always object marked on the verb, other noun classes cannot have an object marker.

${ }^{6}$ The exact reading and status of the object following a focused adverb is unclear at this moment.
} 
(18) a. DJ k-aa-hí-lówá ntsáná ehópa

1sg-REM-DJ-catch yesterday 9.fish

'I caught fish yesterday'

b. CJ kaalówálé ntsáná ehópa / * *ehopá

$i$ * 'I caught yesterday fish'

ii. 'I caught yesterday fish' (not today'

Apart from adverbs, vocatives can also intervene between a DJ verb form and the (new information) object (see also Van der Spuy 1993). ${ }^{7}$ The CJ form is ungrammatical in this situation.

$$
\begin{aligned}
& \text { DJ n-náá-phéélá mpatthání o-tsúwéla? (CJ *mwimphéélá) } \\
& \text { 2.RESP-PRES.DJ-want 1.friend 15-know } \\
& \text { 'do you want, my friend, to know?' }
\end{aligned}
$$

\subsection{Disjoint verb form and change of word order}

This way of looking at the factors determining the choice between the CJ and DJ form of the verb may also help us understand yet another occurrence of the DJ verb form. When putting a contrastive focus on the verb, the disjoint form must be used. It has been claimed by Voeltz (2004) that by using the disjoint verb in sentences otherwise identical "the emphasis is definitely on the verb. The important information transmitted is 'what is being done' and not 'who did it to whom' or 'when' or 'where something was done'." (Voeltz 2004, p.12). He translates this with English "do-support" (20) (see also Güldemann 1996).

Zulu (Voeltz 2004)

(20) a. CJ si-dlal-a ekuseni

we-play-FV in.the.morning

'we play in the morning (not at other times)'

b. DJ si-ya-dlal-a ekuseni

we-DJ-play-FV in.the.morning

'we do play in the morning'

${ }^{7}$ In (19) the infinitive 'to know' is treated as a real object, since in Bantu the infinitive behaves as a noun. It belongs to noun class 15 and is also tonally lowered after a conjoint verb form. 
These Zulu data could form a counterargument to the hypothesis that nothing focal follows a DJ form, since 'in the morning' in (20) follows a DJ verb form and is not particularly familiar or old information. Similar data with CJ/DJ pairs come from Setswana (21).

Tswana (Creissels 1996)

(21) a. CJ ke bína lé ene

1 sg dance and 3sg 'I am dancing with him'

b. DJ ké a bína lé nná

$1 \mathrm{sg}$ DJ dance and $1 \mathrm{sg} \quad$ 'I am dancing too'

However, McCormack (this volume) noted a preference of putting the DJ verb form phrase-finally when re-eliciting these sentences. Instead of only changing a CJ to a DJ form, informants preferred to change the word order as well (22).

$$
\begin{aligned}
& \text { DJ lé nná ké a bína } \\
& \text { and } 1 \text { sg } 1 \text { sg DJ dance }
\end{aligned}
$$

'I am dancing too'

The same effect happens in Makhuwa. Translating sentences like "I work on a boat, I don't sleep there" was very hard or impossible in elicitation sessions, but inversion of the positive and negative sentence immediately made the combination of sentences acceptable (23).

\title{
Makhuwa
}

\author{
n-ki-ń-rúpa n-kaláwá-ni, \\ NEG-1sg-NEG-sleep 18-boat-LOC 'I don't sleep on a boat, \\ DJ ki-náá-lówá (n-kaláwá-ni) \\ 1sg-PRES.DJ-fish 18-boat-LOC I fish on a boat'
}

Apparently the DJ verb form should be in a phrase-final position or, if that is not the case, what follows should be old information. In reversing the sentences, what follows the verb has already been mentioned and thus is not focal. It remains to be seen whether such an effect also holds for Zulu. If not, the data from Zulu pose a potential problem for the hypothesis that the IAV position is empty when the verb appears in its disjoint form. 


\subsection{Complement clause}

There is one more instance where new information follows a DJ verb form, namely when the verb takes a complement clause. The verb form is expected to be $\mathrm{CJ}$, since what follows is new information. However, example (25) shows (more clearly than (24)) that wiíra is a matrix clause complementizer. It thus indicates the beginning of a separate phrase (which can be direct speech) leaving the verb in a position by itself. The verb appears in it DJ form.

$$
\begin{aligned}
& \text { DJ oo-líyála wiírá } \\
& \text { 1.PERF.DJ-forget that } \\
& \text { t-uúlé a-haa-tthúny-ááwé o-ń-túp-íh-a } \\
& \text { COP-1.DEM 1-NEG.impf-want-1.REL 15-1.OM-jump-CAUS-FV } \\
& \text { 'she (hyena) forgot that' OR 'she forgot: } \\
& \text { it was her who didn't want to help him (tortoise) jump' }
\end{aligned}
$$

$$
\begin{aligned}
& \text { DJ yaa-nú-kí-hímeéryá wiírá } \\
& \text { 2.REM-PERS.DJ-1sg.OM-tell that } \\
& \text { o-hi-n-thelé nthíyáná owoóthá } \\
& \text { 2sg-NEG-1.OM-marry-OPT 1.woman 1.lying } \\
& \text { 'they told me that' OR 'they told me: } \\
& \text { "you shouldn't marry a lying woman" ، }
\end{aligned}
$$

In summary, I have shown various occurrences of the disjoint verb form, and, in general, these all obey the constraint that elements following a disjoint verb form are not focal. In order to provide evidence for the hypothesis that the verb has its disjoint verb form when the IAV position is empty, a definition of the IAV position is needed.

The fact that an adverb is allowed to occur in between a DJ verb form and an object suggests that the object in this case is in a position other than an object following a CJ form (18). Furthermore, it suggests that the CJ verb form and the object need to be adjacent, which will be shown to be important in defining the syntactic positions of the CJ and DJ verb form and the positions of their following elements. I come back to the definition of the IAV position later in section 4 and first give a structural analysis explaining the position of the verb in the syntactic representation of a Makhuwa sentence. With the proposed syntactic analysis and definition of the IAV position, the two generalizations are accounted for: 1) a verb appears in its conjoint form when a focal element 
occupies the IAV position; 2) a verb appears in its disjoint form when the IAV position is empty.

\section{$4 \quad$ Syntactic analysis}

\subsection{No verb movement above vP}

In order to come to an analysis of the IAV position and the objects following a CJ or DJ verb form, I will first explain the syntactic model I assume for a Bantu verb sequence. The Bantu verb consists of a verb stem with inflectional prefixes. This verb stem is built up of a verb root and suffixed extensions.

$$
\text { SM-TAM-OM- }\left[\mathrm{V}_{\text {root }}-\text { Ext }\right]_{\text {stem }}-\mathrm{FV}
$$

I follow Kinyalolo (2003, cited in Carstens 2005), Myers (1990), Julien (2002) and Buell (2005) in assuming that the verb starts out as a root and only moves in the lower part of the derivation to incorporate the derivational suffixes. It then terminates in a position lower than $\mathrm{T}$. The inflectional prefixes on the verb represent functional heads spelled out in their base positions. This analysis is supported by several arguments. First, the suffixes are derivational and able to change the valency of the verb, hence they should be in the theta domain (vP). Following Kayne's (1994) asymmetry framework, moved heads adjoin to the left and hence the extensions (the derivational morphemes) are suffixes. There is no reason to assume that a moved head will first incorporate morphemes to its right and then to its left, so the fact that inflectional morphemes surface as prefixes strongly suggests that these are not incorporated in the verb and thus that the verb has not moved further up.

Second, the prefixes are ordered in the exact same way a structure is is standardly assumed to be built up (27b). In other languages where there is evidence that the verb does move, the inflectional morphemes appear in the opposite order as suffixes on the verb (27a). Again this suggests that the prefixes are still in their original position.

(27) a.

\section{a. nous aim-er-i-ons}

1pl love-irr-PAST-1pl

b. n-aa-núú-kúsha

1pl-REM-PERS-carry 'we would love' (French)

"we had carried" (Makhuwa) 
A final clue is that the verb stem by itself should form a constituent, since only the verb stem is the target for reduplication. When emphasizing the durative or iterative aspect of an action, the verb without its inflectional prefixes is reduplicated. In (28) the verb stem -koha is reduplicated without the subject prefix ki- or the tense and disjoint prefix -naa-. ${ }^{8}$

$$
\begin{aligned}
& \text { DJ ki-náá-kóhá-kohá-tsa } \\
& \text { 1sg-PRES.DJ-ask-REDUP-REP }
\end{aligned}
$$

$$
\text { 'I am doing research' }
$$

\subsection{Structural adjacency}

Now I return to the definition of the IAV position. If the IAV position is defined linearly, an object with old information should just as well be in that position as one with new information. After all, what is observed in the sentence is just a verb of some form and an element placed directly after it. So the IAV position is (at least in this case) necessarily defined structurally. Since the conjoint verb form demands that the object be adjacent, I propose to define the IAV position as the position structurally adjacent to the verb. However, there is more than one way to implement structural adjacency.

Structural adjacency is often used in theories about morphological merger. Fuss (2004), inspired by Halle and Marantz (1993), uses the following definition of structural adjacency.

(29) A terminal node $\mathrm{X}$ and the closest terminal node $\mathrm{Y}$ c-commanded by $\mathrm{X}$ are structurally adjacent.

I assume this definition to mean that two closest c-commanding heads, but also a head and the closest c-commanded specifier are structurally adjacent. It will shortly be clear how this definition works in the proposed tree structure.

\subsubsection{Functional projection under $v P$}

Following Baker and Collins (to appear) I assume a functional projection (FP) under small vP. For them, this FP is the LinkerProjection, hosting a particle they refer to as a linker. The function of the particle is not exactly clear, but Baker and Collins analyse it as a Case checker. In Makhuwa there is no (visible) linker, but the projection functions as a low focus projection. Just as in the Linkertheory an argument moves to the specifier of the FP, only here not specifically

\footnotetext{
${ }^{8}$ The plural morpheme -tsa is a clitic, not an extension, which is attached to the verb after reduplication.
} 
for case reasons, but to satisfy a focus reading. ${ }^{9}$ Needless to say, only focal elements can move to this position, for example a focused object or adverb. When the verb then cyclically moves to little $\mathrm{v}$, the verb and the focal element are adjacent; the IAV position is filled (30).

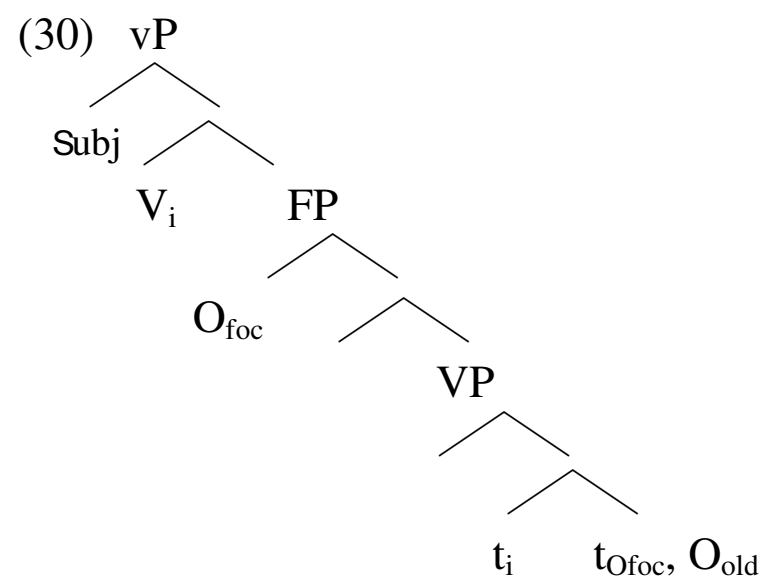

Since the object representing old information does not have a reason to move, it remains in situ, thus creating a structural distance, non-adjacency between the verb and the object. In between the two is room for adverbs. When an adverb is contrastively focused, it moves to specFP and the object simply stays in its original position. What also follows from this analysis is why only the first element following a CJ form is in focus: there is only one FP with one specifier and hence only one element can move and be in focus. ${ }^{10,11}$

\subsubsection{Focus projections and disjoint marking}

A remaining issue is how the verb "knows" whether it should appear segmentally in its conjoint or disjoint form. What is the structure above vP? Carstens (2005) claims that TP universally has an EPP feature and thus the subject moves to specTP. Under TP are the projections for tense morphemes, but also a head/projection to host the marking of the disjoint form. For Rundi,

\footnotetext{
${ }^{9}$ It might also be the case that Baker and Collins's linker is actually a focus marker and the projection turns out to be something with more content than just a 'linker projection'. Unfortunately Baker and Collins provide no information on information structure associated with the various sentences.

${ }^{10}$ This could explain why it is impossible to make multiple questions in Makhuwa. Question words need focus and since only one element can be in the right position to check its focus, the other one will crash the derivation.

${ }^{11}$ Combining this with the double object constructions Baker and Collins (to appear) discuss, one would predict that a double object construction with a focused adverb is impossible. More data are needed to confirm this prediction.
} 
another Bantu language that uses a CJ/DJ distinction, Ndayiragije (1999) proposes a focus projection under TP, exactly at the place where the DJ marker appears in the string of prefixes. I assume the same focus projection for Makhuwa. There now is a parallel structure in the two phases of the derivation $\mathrm{vP}$ and TP, as illustrated in (32) with the disjoint example in (31).

$$
\begin{aligned}
& \text { DJ ki-náá-thípelá epúrí ile } \\
& \text { 1sg-PRES.DJ-bury 9.goat 9.DEM } \\
& \text { 'I am burying that goat' }
\end{aligned}
$$

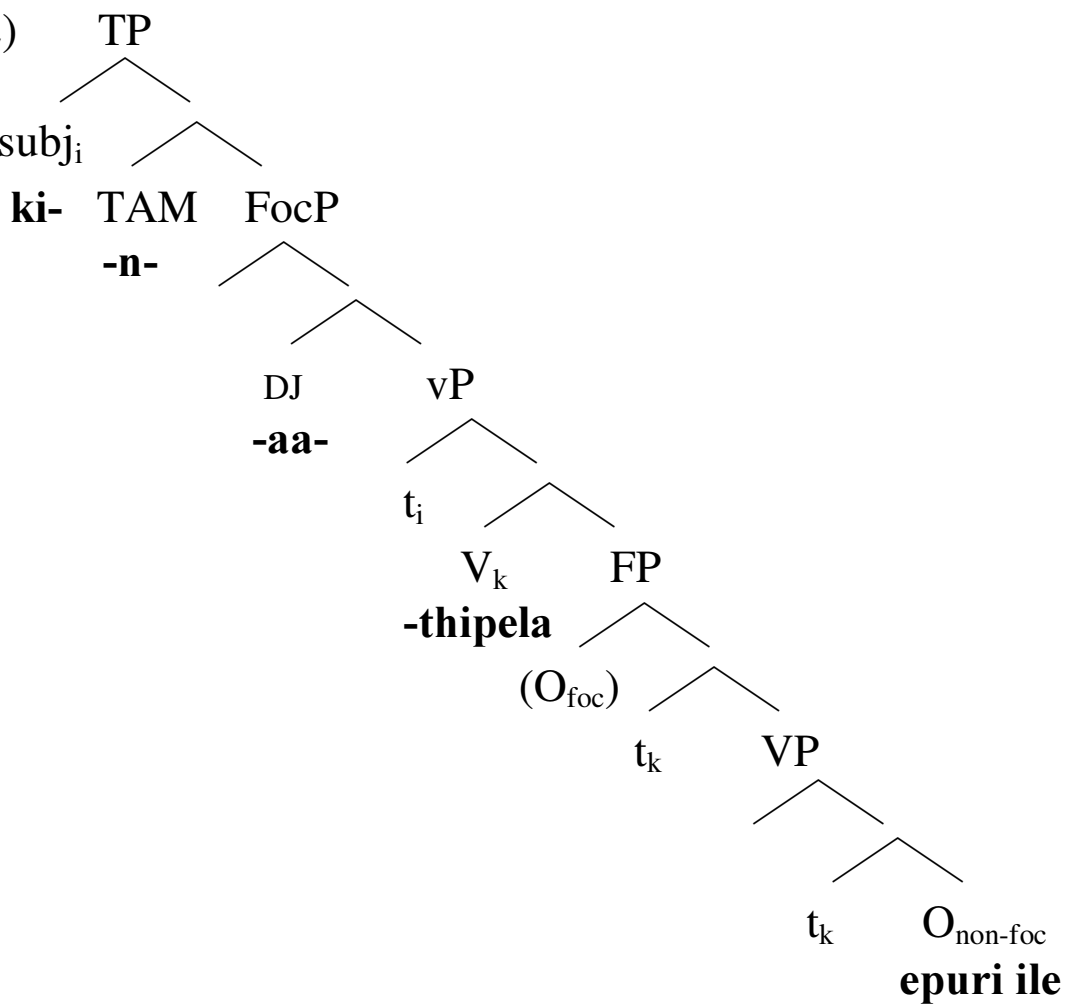

The two Focus projections (high (FocP) as in Ndayiragije 1999 and low (FP) adapted from Baker and Collins) are separate projections with separate functions, but they are related. When the specifier of the low FP is filled by a focal object, the head of the higher (FocP) is zero (CJ form) and when specFP is empty, FocP spells out the DJ marking (DJ verb).
DJ FocP -aa-
specFP (empty)
CJ FocP (empty)
specFP $\mathbf{O}_{\text {foc }}$ 
As already mentioned, the verb moves cyclically from $\mathrm{V}$ to $\mathrm{v}$ via the head of FP. This is where the verb is valued for focus: if the specifier of the lower focus projection is filled by the focal object, the verb is marked [-F]; if the specifier is empty, the verb is valued $[+\mathrm{F}]$. The $\mathrm{vP}$ is then selected by the tense markers in the inflectional domain. Because the inflectional domain merges morphologically to the verb stem, it creates a dependency and can thus see the specification of the verb stem. If it is valued [-F], the inflectional domain knows that there already is a focused element inside the vP and the higher FocP is zero. If the inflectional domain encounters $\mathrm{a}[+\mathrm{F}]$ verb stem in $\mathrm{vP}$, it spells out the DJ marker in (high) FocP.
DJ $\quad$ specFP (empty) >
$\mathrm{V}[+\mathrm{F}]>$
FocP -aa-
CJ $\quad$ specFP $\mathbf{O}_{\text {foc }}>$
$\mathrm{V}[-\mathrm{F}]>$
FocP (empty)

\subsection{An alternative analysis}

The IAV position could alternatively be defined another way, requiring a different syntactic analysis of the data. The most basic definition for structural adjacency is sisterhood of the verb and object. That is, of the focal object and verb, since the object with old information is required to not be in the IAV position and thus not be adjacent to the verb. If a structure is assumed in which the CJ verb and focal object are sisters, the non-focal object with a DJ verb form should be dislocated to the right.

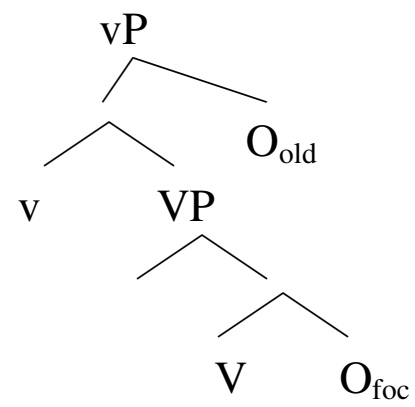

There are several problems with this tree structure. For one, right-adjunction violates Kayne's Linear Correspondance Axiom (Kayne 1994), which states that movement and adjunction universally only proceed in a leftward fashion. This need not be a crucial problem, since the LCA has been contradicted before (see, for example, Ndayiragije 1999). Another, more serious, problem is that it is hard to predict whether a verb will appear in its CJ or DJ form, a point which is captured in the analysis proposed above. And then there is still a third 
problematic case. In example (18) (repeated below) it was mentioned that a sequence VCJ-Adv-O is only correct when the adverb is (contrastively) focused.

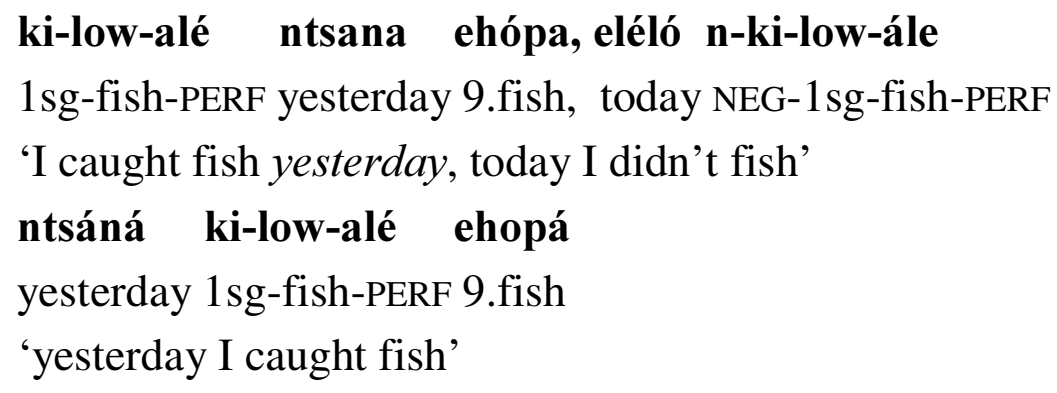

The position of the focused adverb in (18a) should be the same as that of the focused object in (18b), namely the complement and sister of V. If adverbs can at all be selected by verbs, it still leaves the question where the object is in this case. Since I do not see solutions for these counter arguments at the moment, I assume the previously given account is on the right track.

\subsection{A remaining issue: the postverbal subject}

A remaining issue that has not been analysed yet, is the construction with a postverbal subject in Makhuwa. This section gives thoughts and data in order to see whether this construction is a possible counterargument for the analysis proposed here. The postverbal subject is clearly new information and still a DJ verb form is used in Makhuwa, which is not what one would expect. In Aghem and Tswana the postverbal position is often used to give the subject focus. In a neutral sentence in Aghem (36a) the subject typically occupies a preverbal position, but when the subject is focused in an answer to a question, it immediately follows the verb (36c). Tswana uses a postverbal subject to make a presentational construction (37).

Aghem (Watters 1979: 146)

(36) a.

fíl á mò zá kábé án 'sóm

friends SM P2 eat fufu in farm

'the friends ate fufu in the farm'

b. à mò ż́ ndúghó bé-'ḱ́

DS P2 eat who fufu 'who ate the fufu?'

c. (à mò zî) á-fín (bと-'kś)

DS P2 eat friends fufu 'the friends (ate the fufu)' 
Tswana (Demuth and Mmusi 1997: 11)

The difference between the postverbal subject construction in Aghem or Tswana $(36,37)$ and Makhuwa $(38)$ is the agreement with the subject. In the first two languages the subject marker on the verb does not agree with the postverbal subject, but is a dummy subject. In Tswana this non-agreeing subject marker is the prefix of the (originally locative) class 17 . The Makhuwa examples in (38) show that the subject prefix on the verb is not a dummy or a locative, but that it agrees with the postverbal subject. Other evidence that the postverbal subject has a different status in the different languages, is in the nominal morphology of Aghem. The subject in (36a) is sentence-initial and consists of the noun root, whereas in (36c) the subject is in the IAV position and first has the noun class prefix and then the noun root. Other characteristics for Makhuwa are the disjoint form of the verb and the fact that the subject has its original tonal form, i.e., it is not lowered. The sentence in (38a) comes from a story where a man dresses himself as a ghost and appears at his own house where his wife opens the door and receives the message the "ghost" brings. Later, when the man comes back home, his wife tells him that a ghost appeared. (38b) is the normal way of saying that it rained.

\section{Makhuwa}

(38) a. DJ waa-núú-khúmá nnépá wa á-píp' ínyu

3.REM-PERS.DJ-go.out 3.ghost 3.CONN RESP-grandma 2.RESP.POSS

'(there/it) came out the ghost of your grandmother'

b. DJ yoo-rúpá e-púla
9.PERF.DJ-fall 9-rain
'(there) fell rain'

What must be mentioned here is the difference in focus meaning and form. Until now we have come across instances of (new) information focus and contrastive focus and it remains to be seen whether VS structure in Makhuwa expresses one of these focus types or perhaps another kind of information structure. For objects or adjuncts, (new) information focus (39) or contrastive focus (40) are usually expressed after a conjoint form or in a cleft sentence. ${ }^{12}$

\footnotetext{
${ }^{12}$ There is no CJ/DJ distinction in relatives.
} 
Q Hamísí o-n-thíkílá esheení?

1.Hamisi 1-PRES-cut what 'what is Hamisi cutting?'

A Hamísí o-n-thíkíla nthalí

1.Hamisi 1-PRES-cut 3.tree

'Hamisi cuts a tree'

\section{Q esheení n-kíńtálí mmó e-nyákulihíya?}

9.what.COP 18-compound 18.here 9-make.noise

'what is making noise in the compound?'

\section{A nthalí onthíkílááwe Hamísi}

3.tree.COP 3-PRES-cut-REL.1 1.Hamisi

'it is the tree that Hamisi is cutting'

Since a subject can neither follow a conjoint verb form in Makhuwa nor be focused in its normal preverbal position, the only way to focus it (contrastively) is to make a cleft. The focused subject is underlined.

$$
\begin{aligned}
& \text { Q o-n-rúpá ti paní mpáni mmó? Aputuulí? } \\
& \text { 1-PRES-sleep COP who inside here Abdul.COP } \\
& \text { 'Who is sleeping in here? Is it Abdul?' } \\
& \text { (lit. 'who is the one who is sleeping...') } \\
& \text { A ka-hílyó Aputúli, o-n-rúpá ti Joána } \\
& \text { NEG-DEM Abdul 1-PRES-sleep COP Joanna } \\
& \text { 'It's not Abdul; who is sleeping is Joanna.' }
\end{aligned}
$$

Since contrastive focus on the subject is expressed by means of a cleft, the focus expressed in a VS construction must be another type of focus, presumably presentational focus. This term is somewhat misleading since what is in focus is actually the whole sentence (Lambrecht's (1994) Sentence Focus). The VS sentences are entity-central thetic utterances: "an entity-central thetic statement is a type of utterance stating the existence of an entity" (Sasse 1987, p.526). All information in the sentence is new and therefore a theme-rheme or entitypredication relation cannot be established. In this way the information structure in these presentational sentences is on a higher level than sentence-internal focus. It would thus not violate the hypothesis that an element following a DJ 
verb form is not focal. Even if so, a syntactic account should be given of the structure and interpretation, which could include the hypothesis that in Aghem and Tswana the subject is indeed in the IAV position, whereas in Makhuwa it is not.

\section{Conclusions}

In this paper two generalisations are made on the distribution of the conjoint and disjoint verb forms in Makhuwa. 1) A verb appears in its conjoint form when a focal element occupies the IAV position; 2) a verb appears in its disjoint form when the IAV position is empty. A syntactic analysis is provided that accounts for these generalisations if the IAV position is defined in terms of structural adjacency between two heads in a direct c-command relation.

In the syntactic analysis two focus projections were proposed: one under TP (Ndayiragije 1999) hosting the disjoint morpheme and one under vP, to the specifier of which focal elements move. Non-focal elements remain in-situ. This analysis accounts both for the strong adjacency of a conjoint verb form and its focal object and for the empty IAV position that requires a verb to appear in its disjoint form.

Topics for further research include postverbal subject construction (in both an agreeing and non-agreeing form, e.g. Makhuwa and Zulu) and the mapping of phonological or prosodic phrasing onto this syntactic structure. It will be difficult to do this for Makhuwa, since there are no strong indications for phrase boundaries (such as penultimate lengthening in other languages), but since the syntactic analysis should work for more languages with CJ/DJ systems, one of the next steps is to look at languages like Tswana, Zulu, Makwe or Rundi and test the predictions made in/from this paper.

\section{References}

Baker, Mark and Chris Collins (to appear). Linkers and the internal structure of vP. Natural Language and Linguistic Theory.

Buell, Leston C. 2005. Issues in Zulu Morphosyntax. Ph. D. thesis, University of California, Los Angeles.

Carstens, Vicky (2005). Agree and EPP in Bantu. Natural Language and Linguistic Theory 23: $219-279$.

Creissels, Denis (1996). Conjunctive and disjunctive verb forms in Setswana. South African Journal of African Languages 16-4: 109-115.

Demuth, Katherine (1989). Maturation and the acquisition of the Sesotho passive. Language 65: 56-80.

Demuth, Katherine and Sheila Mmusi (1997). Presentational focus and thematic structure in comparative Bantu. Journal of African Languages and Linguistics 18: 1-19. 
Fuß, Eric. 2004. The rise of agreement. A formal approach to the syntax and grammaticalization of verbal inflection. Ph. D. thesis, University of Frankfurt/Main.

Güldemann, Tom (1996). Verbalmorphologie und Nebenprädikation im Bantu. Bochum: Universitätsverlag Dr. N. Brockmeyer.

Halle, Morris and Alec Marantz (1993). Distributed Morphology and the Pieces of Inflection. In: K. Hale and S.J. Keyser, eds., The view from building 20, Cambridge, Massachusetts: MIT Press, 111-176.

Julien, Marit (2002). Syntactic heads and word formation. Oxford University Press, Oxford.

Katupha, José M. M. (1983). A preliminary description of sentence structure in the Esaaka dialect of Emakhuwa. M. Phil. thesis, SOAS, London.

Kayne, Richard (1994). The antisymmetry of syntax. Cambridge, Massachusetts: MIT Press.

Kinyalolo, Kasangati K.W. (2003). Limiting the scope of V-movement in Kilega. Handout of a talk given at Stony Brook, New York.

Lambrecht, Knud. 1994. Information structure and sentence form. Cambridge: Cambridge University Press.

Meeussen, A. E. (1959). Essaie de grammaire Rundi. Annales du Musée Royal du Congo Belge, Série Sciences Humaines, 24, Tervuren.

McCormack, Anna (2006). A further look at conjunctive and disjunctive forms in Setswana, this volume.

Myers, Scott (1990). Tone and the structure of words in Shona. New York: Garland.

Ndayiragije, Juvénal (1999). Checking economy. Linguistic Inquiry 30: 399-444.

Sasse, Hans Jürgen (1987). The thetic/categorical distinction revisited. Linguistics 25: 511580.

Schadeberg, Thilo and Francisco Mucanheia (2000). Ekoti. Cologne: Rüdiger Köppe Verlag.

Selkirk, Elisabeth (1984). Phonology and Syntax: therrelation between sound and structure. Cambridge, Massachusetts: MIT Press

Stucky, Susan U. (1979). The interaction of tone and focus in Makua. Journal of African Languages and Linguistics 1: 189-198.

Van der Spuy, A. (1993). Dislocated NPs in Nguni. Lingua 90: 335-355.

Van Valin, Robert (1999). A typology of the interaction of focus structure and syntax. In: E. Raxilina and J. Testelec (eds.) Typology and the theory of language: from description to explanation: 511-524. Moscow: Languages of Russian Culture.

Voeltz, Ehrhard F.K. (2004). Long and short verb forms in Zulu. Paper for ACAL Boston.

Watters, John (1979). Focus in Aghem. In: L. Hyman (ed.) SCOPiL Aghem grammatical structure. Los Angeles: University of Southern California.

Zerbian, Sabine (2006). Expression of information structure in Northern Sotho. Ph. D. thesis, Humboldt University, Berlin.

j.van.der.wal@let.leidenuniv.nl 